(From the Laboratory of Microbiology, Technological University, and the Yeast Division, Centraalbureau voor Schimmelcultures, Delft, the Netherlands).

\title{
ON THE EXISTENCE OF A NEGATIVE PASTEUR EFFECT IN YEASTS CLASSIFIED IN THE GENUS BRETTANOMYCES KUFFERATH ET VAN LAER
}

by

T. WIKEN, W. A. SCHEFFERS and A. J. M. VERHAAR ${ }^{1}$ )

(Received June 28, 1961).

\section{INTRODUCTION.}

Even at a mere glance at the extensive literature on the influence of elementary molecular oxygen on the alcoholic fermentation in living yeast cells and various yeast preparations it is evident that so far most works have been concerned with the in hibiting e $\mathrm{f} \mathrm{e} \mathrm{ct}$ produced by this gas on the rate and extent of the process mentioned. Particularly the relation between the anoxybiontic fermentation and the respiration as measured by the oxygen consumption was and still is one of the main subjects of investigation and speculation. This state of things is confirmed strikingly on studying recent volumes on cellular biochemistry like the "Proceedings of the International Symposium on Enzyme Chemistry, Tokyo and Kyoto 1957", and the "Ciba Foundation Symposium on the Regulation of Cell Metabolism", which appeared in 1958 and 1959 , respectively.

The present paper, on the other hand, deals with the sti m u$\mathrm{l}$ a $\mathrm{t}$ in $\mathrm{g}$ ef f e c $\mathrm{t}$ produced by elementary molecular oxygen on the rate of alcoholic fermentation in living cells of yeasts classified in the genus Brettanomyces Kufferath et van Laer. If we agree upon the definition of the concept of the "Pasteur effect" given for historical reasons by BURK (1939) as an inhibition of fermentative

1) Present address: N.V. Industriële Onderneming W. H. Braskamp, Voorburg (Z.H.), the Netherlands. 
processes caused by gaseous oxygen, then the phenomenon described in this paper, i.e. the inhibition of alcoholic fermentation under strictly anaerobic conditions and its stimulation in presence of molecular oxygen, may be named a "negative Pasteur effect". As a matter of fact, this term was proposed in the sense mentioned as early as in 1940 by CUSTERg in his classical work on the Brettanomyces yeasts. When using the term we are, of course, fully aware of the fact that the corresponding physiological effects are not necessarily caused by one and the same mechanism in different yeasts and under different environmental conditions, but rather may be due to a number of mechanisms acting at different steps in the sequence of reactions resulting in breakdown of the sugar molecule to ethyl alcohol and carbon dioxide.

As mentioned above Custers (1940) discovered a negative Pasteur effect in investigating the alcoholic fermentation of a Brettanomyces yeast, viz. Br. claussenii Custers. The cells examined by this author by means of the manometric method according to WARBURG originated from plate cultures grown for 3 to 7 days at $30^{\circ} \mathrm{C}$. on malt agar supplied with chalk for neutralizing the acetic acid formed ( $c$. below). The harvested cells were washed twice in tap water and then suspended in a 2.5 per cent solution of primary potassium phosphate at $\mathrm{pH} 4.4-4.5$. A phosphate solution of the same strength and $\mathrm{pH}$ was used in dissolving the glucose to be dissimilated aerobically or anaerobically. Immediately after mixing of cell suspension and glucose solution the sugar concentration was 2 per cent. The total volume of fluid per Warburg vessel amounted to $2.0 \mathrm{ml}$ and the yeast dry substance to $2.72-5.92 \mathrm{mg}$. Anaerobic conditions were obtained by flushing during 20 minutes with nitrogen freed of oxygen by passing over copper gauze at $500^{\circ} \mathrm{C}$. The sugar dissimilation was measured at $30^{\circ} \mathrm{C}$.

Under the experimental conditions summarized briefly above Custers (1940) observed a negative Pasteur effect in cells from 3 days old yeast cultures grown in air, when the cell suspension and glucose solution initially present in the main compartment and side arm of the Warburg vessels, respectively, were mixed after the pretreatment with oxygen-free nitrogen or air for ensuring anaerobiosis and aerobiosis. In examining the fermenting power of cells from cultures grown for 7 days under aerobic conditions Custers, on the other hand, found a normal Pasteur effect, i.e. the rate of fermentation in oxygen-free nitrogen surpassed that in air. In these 
experiments, however, the sugar solution was added to the yeast suspensions $\mathrm{p} r$ e vi o us to the pretreatment with nitrogen or air. According to our experience the results thus obtained with the cells from old cultures, because of the difference in experimental conditions, cannot be compared with those mentioned above for the cells from young cultures. As a matter of fact, no negative Pasteur effect at all or only a minute one was observed by CusTERs in yeast from young cultures on addition of sugar to the cell suspensions previous to flushing with oxygen-free nitrogen or air.

According to a hypothesis proposed by Lipmann (1933, 1934, 1942) the normal Pasteur effect, i.e. the inhibition of fermentation under aerobic conditions, is due to a reversible oxidative inactivation of an essential part of the glycolytic enzyme system produced by the respiratory enzymes in presence of molecular oxygen. In analogy with this hypothesis Custers (1940) made the assumption that the negative Pasteur effect in the cells of $\mathrm{Br}$. claussenii is caused by a reversible reductive inactivation of the proper enzyme system taking place under strictly anaerobic conditions.

In examining the anaerobic and aerobic dissimilation of glucose by proliferating and resting cells of Br. claussenii CUSTERS (1940) further showed that ethyl alcohol and carbon dioxide are the only end products formed in nitrogen, while in air in addition appreciable amounts of acetic acid are being produced. In manometric experiments under aerobic conditions with ethyl alcohol as a substrate CUsters found that at pH $6.4-6.8$ the alcohol is oxidized to acetic acid only, whereas at $\mathrm{pH} 3.8-4.4$ the primarily formed acetic acid undergoes a complete oxidation to carbon dioxide and water.

The present study was undertaken in order to obtain further information about the existence of a negative Pasteur effect in whole cells of yeasts classified in the genus Brettanomyces Kufferath et van Laer according to LODDER and KREGER-VAN RIJ (1952). In addition, we have examined some yeasts which earlier actually were described as Brettanomyces species or at least were suspected to be closely related or even belong to this genus but at present are placed in the genera Hansenula $\mathrm{H}$. et P. Sydow and Torulopsis Berlese. Finally, we tested two yeasts considered as not being definitely or precisely determined, and three yeasts included in the genus Saccharomyces (Meyen) Reess and characterized by a comparatively strong production of acetic acid. 


\section{Materials and Methods.}

Y e a st strains. So far the following Brettanomyces species and strains were examined:

Br. anomalus Custers; two strains: CBS 77 and CBS 3026.

$B r$. bruxellensis Kufferath et van Laer; four strains: CBS 72, CBS 73, CBS 74 and CBS 96.

Br. bruxellensis Kufferath et van Laer var. non-membranaefaciens Custers; four strains: CBS 78, CBS 97, CBS 98 and CBS 3025.

$B r$. clanssenii Custers; two strains: CBS 76 and CBS 1938.

$B r$ lambicus Kufferath et van Laer; one strain: CBS 75.

Br. schanderlii Peynaud et Domercq (see PEYNAUd and DomerCQ, 1956); two strains: CBS 2796 and CBS 2797.

Br. vini (Barret, Bidan et André) Peynaud et Domercq (see Peynaud and Domerco, 1956); seven strains: CBS 1940, CBS 1941, CBS 1942, CBS 1943, CBS 2336, CBS 2499 and CBS 2547.

For form's sake it may be added that the strains Br. bruxellensis CBS 72 and CBS 74, Br. bruxellensis var. non-membranaefaciens CBS 78, and Br. lambicus CBS 75 according to VAN DER WALT and VAN KERKEN (1959a) should be united into a single species, viz. $B r$. bruxellensis. The same authors, furthermore, point out the close relationship of the strain $B r$. bruxellensis CBS 73 to the strain $B r$ vini CBS 1943 and to a strain $B r$. vini Bordeaux 48 which probably is identical with our strain $B r$. vini CBS 2499 . These three strains are brought into one species, Br. intermedius Krumbholz et Tauschanoff (nov. comb.).

Of the yeasts which earlier were included in the genus Breltanomyces or suspected to be closely related to this genus but at present are brought into the genera Hansenula and Tornlopsis the following were tested:

Hansenula anomala (Hansen) H. et P. Sydow; one strain: CBS 1690. This strain was originally obtained from Kufferath in 1927 under the name of Willia lambica Kufferath. It was then listed in the catalogue of CBS for 193 I and described by BEDFORD (1942) as Hansenula lambica (Kufferath) Dekker. BEDFoRD pointed out (p. 640) that the characteristics of this species agree with those given by Custers (1940) for Brettanomyces lambicus. However, LODDER and KREGER-VAN RIJ (1952, p. 257) on basis of a comparative study of both organisms state that these cannot belong to one and the same species. By way of example, the former strain shows 
normal growth on malt agar and may be successfully transferred to a new substrate after a period of six months, whereas the latter organism shows the typical Brettanomyces properties of slow growth on malt agar and early death of the cells because of vigorous production of acetic acid. For these and other reasons LODDER and KREGER-VAN RIJ classify the strain CBS 1690 as Hansenula anomala.

Tornlopsis anomala Lodder et Kreger-van Rij; one strain: CBS 1731. This strain was isolated from a high-salt cucumber brine during the latter stage of fermentation by ETCHELLS and BELL (1950) and was considered by these authors a variety of Brettanomyces versatilis Etchells et Bell (cf. LODDER and KREGER-VAN RIJ, 1952, p. 431).

To. bacillaris (Kroemer et Krumbholz) Lodder; five strains: CBS 843, CBS 1713, CBS 1779, CBS 2649 and CBS 2799. Of these strains CBS 843 was isolated and described by KROEMER and KRUMBHOLZ (1931) and KRumbiolz (1931) as Saccharomyces bacillaris. The yeast CBS 1713 was obtained from VERONA as an authentic strain of the species Brettanomyces italicus described by VERONA and FLORENZANO (1947). In studying this organism LODDER and KREGER-VAN RIJ (1952, pp. 423-425) could not confirm the observations reported by the Italian authors in the description and diagnosis of $\mathrm{Br}$. italicus with the exception of the property that the cultures lose viability earlier than most other yeasts.

To. etchellsii Lodder et Kreger-van Rij; four strains: CBS 1750 , CBS 1751, CBS 2853 and CBS 2854. Of these strains CBS 1750 and CBS. 1751 were isolated from high-salt cucumber brines during the latter part of fermentation by ETCHELLS and BELL (1950) and named Brettanomyces sphaericus. On having studied the properties of these strains carefully LODDER and KREGER-VAN RIJ (1952, pp. 431 and 428-429) came to the conclusion that they hardly show any relation to the genus Brettanomyces.

To. versatilis (Etchells et Bell) Lodder et Kreger-van Rij; nine strains: CBS 1752, CBS 1753, CBS 1754, CBS 1755, CBS 1756, CBS 1757, CBS 1758, CBS 1759 and CBS 1760. The first eight strains (CBS 1752-1759) were isolated by ETCHELLS and BELL (1950) from cucumber brines of extremely high salt strength during the latter stage of fermentation. They were included by the American authors in the genus Breltanomyces as a new species named $B r$. versalilis. The results of a careful study of the properties of these strains induced LodDer and KREger-VAN RIJ (1952, pp. 428-430) to 
remove them from the genus Brettanomyces and include them in the genus Tornlopsis as To. versatilis.

In addition, Torulopsis apicola Hajsig, viz. strain CBS 2868, isolated from the intestinal tract of a bee and described by HaJsIG (1958), and To. stellata (Kroemer et Krumbholz) Lodder, viz. strain CBS 157, isolated from a grape must with a high sugar concentration (cf. LOdDER and KREger-vaN RiJ, 1952, pp. 420-422), were examined.

The following two yeasts were tested for presence of a negative Pasteur effect because of their questionable classification:

Unnamed variety of Bretlanomyces sphaericus Etchells et Bell; three strains: CBS 1887, CBS 1888 and CBS 1889. These strains were isolated from fermenting cucumber brines and provisionally considered as a variety of $B r$. sphaericus by ETCHELLS and BELL (1952). As mentioned above, this species is classified at present as Torulopsis etchellsii (LODDER and KREGER-VAN RIJ, 1952).

Torulopsis cylindrica Walters; one strain: CBS 1947. The strain was isolated from infected beer and described by WALTERS (1943; see also Walters and Thiselton, 1953). According to this author the strain must be regarded as an exceedingly virulent beer-disease organism capable of causing complete spoilage of the beer when present in the pitching yeast even in an amount of only 0.001 per cent.

As representatives for yeasts, which are not classified in the genus Brettanonyces but nevertheless produce comparatively large amounts of acetic acid, the following Saccharomyces species were included in our examination:

Sa. aceti Santa María; three strains: CBS 4054, CBS 4070 and CBS 4071. These strains were isolated by SANTA María (1958) from red wine of Spanish origin. They are capable of forming a film or pellicle on wine and other liquid media supplied with ethyl alcohol as well as on grape must which has undergone alcoholic fermentation.

$S a$ acidifaciens (Nickerson) Lodder et Kreger-van Rij; one strain: CBS 749. This strain was isolated from a bottle of domestic red wine turning sour, and describet by Nickerson (1943) as Zygosaccharomyces acidifaciens.

Sa. oxidans Santa María; three strains: CBS 4079, CBS 4092 and CBS 4093. SANTA MARÍA (1958) isolated these strains from a white wine of Spanish origin. Like the strains of $S a$ acei mentioned above they are able to form a film or pellicle on wine or grape must after fermentation. 
As regards the origin and properties of the yeast strains listed above but not commented upon we refer to LODDER and KREGERVAN RIJ (1952) and to the Yeast Division, Centraalbureau voor Schimmelcultures, Laboratory of Microbiology, Delft.

$\mathrm{Culture} \mathrm{media}$. In growing the yeasts mentioned the following liquid substrates were used:

Medium I and Medium II contained the same amounts of sugar and minerals, viz.

$\begin{array}{lc}\text { Glucose } & 50.0 \mathrm{~g} \\ \left(\mathrm{NH}_{4}\right)_{2} \mathrm{SO}_{4} & 6.0 \mathrm{~g} \\ \mathrm{KH}_{2} \mathrm{PO}_{4} & 2.0 \mathrm{~g} \\ \mathrm{MgSO}_{4} \cdot 7 \mathrm{H}_{2} \mathrm{O} \text { and CaCl} & 0.25 \mathrm{~g} \text { each } \\ \mathrm{H}_{3} \mathrm{BO}_{3}, \mathrm{ZnSO}_{4}, \mathrm{MnCl}_{2} \text { and } \mathrm{Tl}_{2} \mathrm{SO}_{4} & 1.0 \mathrm{mg} \text { each } \\ \mathrm{FeCl}_{3} & 0.5 \mathrm{mg} \\ \mathrm{CuSO}_{4} \text { and } \mathrm{KI} & 0.1 \mathrm{mg} \text { each } \\ \text { Distilled water to make } & 1000.0 \mathrm{ml}\end{array}$

The $\mathrm{pH}$ value of the media was adjusted to $6.2-6.4$. In addition Medium I was supplied with $25 \mu \mathrm{g}$ of biotin and $0.5 \mathrm{mg}$ of thiamin per $1000 \mathrm{ml}$ ( $c$. Peynaud and Domerco, 1956), and Medium II with $25 \mu \mathrm{g}$ of biotin, $0.5 \mathrm{mg}$ of thiamin, $0.5 \mathrm{mg}$ of pyridoxin, $2.5 \mathrm{mg}$ of pantothenic acid (calcium salt), $2.5 \mathrm{mg}$ of riboflavin, $25 \mathrm{mg}$ of meso-inositol, and $100 \mathrm{mg}$ of niacin per $1000 \mathrm{ml}$. For details in the preparation of these media we refer to WIKÉN and RICHARD (1951, pp. 212-213, nutrient solution B).

Medium III contained 2 per cent glucose in yeast water (prepared from $200 \mathrm{~g}$ of pressed baker's yeast and $1000 \mathrm{ml}$ of tap water) and had an initial $\mathrm{pH}$ value of $6.2-6.4$.

The yeast cells used in the fermentation experiments were grown in shake cultures in $100 \mathrm{ml}$ Florence flasks containing $25 \mathrm{ml}$ of one of the liquid media mentioned. These were inoculated with cells raised on malt agar slants which were supplemented with chalk for neutralization of the acicl or acids produced. All cultures were kept at $30^{\circ} \mathrm{C}$. For the shake cultures the time of incubation varied from 16 to 90 hours (see the proper tables). The cells were harvested by centrifugation at $3000 \mathrm{rpm}$, washed three times in distilled water and resuspended in fresh distilled water.

Ma nometric methods. The suspensions of "resting" yeast cells prepared as described above were examined for fermentation power by means of standard Warburg manometric techniques (UMBREIT et al., 1957). The Warburg vessels contained $1.8 \mathrm{ml}$ of cell 
suspension, corresponding to $20 \mathrm{mg}$ of wet yeast, in the main compartment and $0.2 \mathrm{ml}$ of $1.0 \mathrm{M}$ solution of glucose in distilled water in the side arm. In measuring the oxygen uptake the carbon dioxide liberated was absorbed in $0.2 \mathrm{ml}$ of 20 per cent potassium hydroxide placed in the center cup, which, in addition, contained a roll of analytical grade filter paper for increasing the surface of the alkali.

Anaerobic conditions were obtained in the Warburg vessels by flushing with purified cylinder nitrogen during 30 minutes previous to addition of the sugar to the yeast suspensions. In the earlier experiments this nitrogen was freed of oxygen by passing through a strongly alkaline pyrogallol solution (see KÜSTER, 1921, p. 71; Wirien and Richard, 1953a, p. 282; Metzger and Müller, 1959, p. 332), and an alkaline solution of sodium hyposulphite (dithionite, hydrosulphite) containing sodium anthraquinone- $\beta$-sulphonate as a catalyst (see FiESER, 1924; VOGEL, 1951, p. 182; 1957, p. 186; Reich and Kapenekas, 1957; Metzger and Müller, 1959, p. 333). In later experiments the traces of molecular oxygen present in the cylinder nitrogen were removed by passage at room temperature over a catalyst containing finely divided palladium deposited uniformly on purified and finely shredded analytical grade asbestos fibers (see ZELINSKy and Borisoff, 1924; WinkLer and BRUNCK, 1919 , p. $190 ; 1927$, p. 171$)$. Before use the palladium catalyst was saturated with gaseous hydrogen.

Aerobic conditions were obtained by shaking in air during 30 minutes before mixing the sugar solution and yeast suspension present in the side arm and main compartment of the Warburg vessels, respectively.

All Warburg experiments were performed at a temperature of $30^{\circ} \mathrm{C}$. The fermentations as well as the respirations were generally run in duplicate or triplicate. In the tables the symbols $M$ and a are used to indicate the mean values and mean deviations, respectively.

In comparing the rates of alcoholic fermentation under anaerobic and aerobic conditions, respectively, the respiration in the sense of an actual uptake of elententary molecular oxygen $\left(\mathrm{O}_{2}\right)$ with incomplete or complete oxidation of the sugar or of the ethyl alcohol, formed in fermentation, must be taken into consideration. For the purpose of a discussion some definitions will be given in order to avoid confusion. This is necessary in view of the fact that the meaning of the terms concerned has changed in course of time and still differs with various authors and investigators. 
The term respiration is, as mentioned above, here confined to mean the uptake of gaseous oxygen in oxidation of a substrate, whereas the term fermentation is used for a substrate transformation occurring without uptake of this gas. Metabolic processes taking place in presence of molecular oxygen are called aerobic, whether or not the oxygen is being utilized in the reactions concerned, while processes taking place in absence of this gas are named anaerobic. The term oxybiontic (oxybiotic) is applied to transformations accompanied by uptake of molecular oxygen. Processes occurring without employing gaseous oxygen are called anoxybiontic (anoxybiotic). Thus the last two terms are used here to cover the dissimilation reactions distinguished by numerous authors as oxidative and anoxidative or fermentative processes, respectively ( $c f$. PASTEUR, 1876; Weinland, 1906; Kluyver, 1924; Kluyver and Donker, 1925, 1926; Bernhauer, 1939, pp. 14-15; Stephenson, 1939, p. 16 ; WerkMAN and WOOD, 1942, pp. 25-26; PORTER, 1946, pp. 794-795 and 896-897; MCBEe, LAMANNA and WeEks, 1955).

In consequence of the above definitions a fermentation is an anoxybiontic process which may take place under anaerobic as well as aerobic conditions, whereas respiration is an oxybiontic process and thus may occur only under aerobic conditions. We will recur to these definitions elsewhere in connection with a discussion of the mechanism of the negative Pasteur effect in Brettanomyces and Saccharomyces yeasts.

$\mathrm{Calculat}$ i o $\mathrm{n}$ of the results. In evaluating the results obtained in the manometric experiments on a erobic sugar dissimilation the following alternatives may be distinguished:

1. The non-proliferating yeast cells do not show any respiration but only fermentation according to the well-known formula:

$$
\mathrm{C}_{6} \mathrm{H}_{12} \mathrm{O}_{3} \rightarrow 2 \mathrm{CO}_{2}+2 \mathrm{CH}_{3} \cdot \mathrm{CH}_{2} \mathrm{OH}
$$

If $h^{2}$ represents the change in the manometer reading (in $\mathrm{mm}$ ) of the flask without alkali in the center cup and $\mathrm{k}^{2} \mathrm{CO}_{2}$ the flask constant for carbon dioxide, then we get the amount of this gas formed in aerobic fermentation as follows:

$$
\mu 1 \mathrm{CO}_{2}^{\text {ferm }}=\mathrm{h}^{2} \times \mathrm{k}^{2} \mathrm{CO}_{3}
$$

This expression may, of course, also be used when the rate of respiration is negligible as compared to that of fermentation.

2 . The yeast cells show marked respiration in addition to fermen- 
tation, the end products of aerobic dissimilation being carbon dioxide, ethyl alcohol, acetic acid and water according to the following formulae:

$$
\begin{aligned}
& \mathrm{C}_{6} \mathrm{H}_{12} \dot{\mathrm{O}}_{6} \rightarrow 2 \mathrm{CO}_{2}+2 \mathrm{CH}_{3} \cdot \mathrm{CH}_{2} \mathrm{OH} \\
& \mathrm{n} \mathrm{CH}_{3} \cdot \mathrm{CH}_{2} \mathrm{OH}+\mathrm{n} \mathrm{O}_{2} \rightarrow \mathrm{n} \mathrm{CH} \cdot \mathrm{COOH}+\mathrm{n}_{2} \mathrm{O}
\end{aligned}
$$

Combining of the two formulae results in the expression:

$$
\mathrm{C}_{6} \mathrm{H}_{12} \mathrm{O}_{6}+\mathrm{n} \mathrm{O}_{2} \rightarrow 2 \mathrm{CO}_{2}+(2-\mathrm{n}) \mathrm{CH}_{3} \cdot \mathrm{CH}_{2} \mathrm{OH}+\mathrm{nCH}_{3} \cdot \mathrm{COOH}+\mathrm{nH}_{2} \mathrm{O}
$$

In this expression the value of $n$ may vary between 0 and 2 . If $\mathrm{n}$ is set equal to 0 , the formula for alternative 1 (see above) is obtained, and if $\mathrm{n}$ equals 2 , the expression assumes the same form as results on substituting 0 for $\mathrm{n}$ in the over-all formula for alternative 3 (see below).

If $h^{1}$ is the change in the manometer reading of the flask with alkali in the center cup and $\mathrm{k}^{\mathrm{I}} \mathrm{O}_{2}$ is the constant of the flask for oxygen, then the amount of this gas taken up in respiration is obtained as follows:

$$
\mu \mathrm{l} \mathrm{O}{ }_{2}^{r e s p}=\mathrm{h}^{1} \times \mathrm{k}^{1} \mathrm{O}_{\mathrm{g}}
$$

From the formulae it appears that carbon dioxide is not formed in respiration but originates entirely from fermentation. Hence:

$$
\mu \mathbf{l ~} \mathrm{CO}_{2} \text { resp }=0
$$

Further, the observed change in the manometer reading of the flask without alkali in the center cup, $\mathrm{h}^{2}$, results from the decrease in pressure due to oxygen uptake in respiration, $\mathrm{h}^{2} \mathrm{a}$, and the increase in pressure due to carbon dioxide formation in fermentation, $\mathrm{h}^{2}{ }_{\mathrm{b}}$. If $\mathrm{k}^{2} \mathrm{O}_{2}$ and $\mathrm{k}^{2} \mathrm{CO}_{2}$ are the constants of this flask for oxygen and carbon dioxide, respectively, we get:

and

$$
\mathrm{h}_{\mathrm{a}}^{2}=\frac{\mu 1 \mathrm{O}_{2}{ }^{\text {resp }}}{\mathrm{k}^{2} \mathrm{O}_{\mathrm{s}}}=\mathrm{h}^{1} \times \frac{\mathrm{k}^{1} \mathrm{O}_{\mathrm{g}}}{\mathrm{k}^{2} \mathrm{O}_{\mathrm{a}}}
$$

Thus:

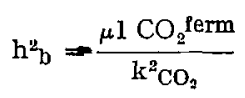

$$
\mathrm{h}^{2}=\mathrm{h}^{2}{ }_{\mathrm{b}}-\mathrm{h}^{2}{ }_{\mathrm{a}}=\frac{\mu \mathrm{IC \textrm {CO } _ { 2 }}{ }^{\text {Perm }}}{\mathrm{k}^{2} \mathrm{CO}_{2}}-\frac{\mu 1 \mathrm{O}_{2}^{\text {resp }}}{\mathrm{k}^{2} \mathrm{O}_{3}}
$$

or

$$
\mathrm{h}^{2} \times \mathrm{k}^{2} \mathrm{CO}_{2}=\mu \mathrm{l} \mathrm{CO}{ }_{2}^{\text {ferm }}-\mu \mathrm{l} \mathrm{O} \mathrm{O}_{2}^{\text {resp }} \times \frac{\mathrm{k}^{2} \mathrm{CO}_{2}}{\mathrm{k}^{2} \mathrm{O}_{2}}
$$


and

$$
\mu \mathrm{I} \mathrm{CO} \mathrm{Cerm}_{2}^{\mathrm{ferm}}=\mathrm{h}^{2} \times \mathrm{k}^{2} \mathrm{CO}_{2}+\mu \mathrm{l} \mathrm{O} \mathrm{O}_{2}^{\text {resp }} \times \frac{\mathrm{k}^{2} \mathrm{CO}_{9}}{\mathrm{k}^{2} \mathrm{O}_{3}} .
$$

This equation may, on the assumptions stated above, be applied in calculating the actual amount of carbon dioxide formed in aerobic fermentation.

3. The yeast cells show marked respiration as well as fermentation with formation of carbon dioxide, acetic acid and water as end products according to the formulae:

$$
\begin{aligned}
& \mathrm{C}_{6} \mathrm{H}_{12} \mathrm{O}_{6} \rightarrow 2 \mathrm{CO}_{2}+2 \mathrm{CH}_{3} \cdot \mathrm{CH}_{2} \mathrm{OH} \\
& 2 \mathrm{CH}_{3} \cdot \mathrm{CH}_{2} \mathrm{OH}+2 \mathrm{O}_{2} \rightarrow 2 \mathrm{CH}_{3} \cdot \mathrm{COOH}+2 \mathrm{H}_{2} \mathrm{O} \\
& \frac{\mathrm{n}}{2} \mathrm{CH}_{3} \cdot \mathrm{COOH}+\mathrm{n} \mathrm{O}_{2} \rightarrow \mathrm{n} \mathrm{CO} \mathrm{CO}_{2}+\mathrm{n}_{2} \mathrm{O} .
\end{aligned}
$$

Combining of the three formulae yields the expression:

$$
\mathrm{C}_{6} \mathrm{H}_{12} \mathrm{O}_{6}+(2+\mathrm{n}) \mathrm{O}_{2} \rightarrow(2+\mathrm{n}) \mathrm{CO}_{2}+\left(2-\frac{\mathrm{n}}{2}\right) \mathrm{CH}_{3} \cdot \mathrm{COOH}+(2+\mathrm{n}) \mathrm{H}_{2} \mathrm{O} \text {. }
$$

In this expression the value of $n$ may vary in the range of 0 to 4. If $\mathrm{n}$ is equal to 0 , the expression is identical with that obtained on substituting 2 for $\mathrm{n}$ in the over-all formula for alternative 2 (see above). In the case $n$ equals 4 , the expression is formally the same as that representing cells with only respiration resulting in complete oxidation of the sugar to carbon dioxide and water:

$$
\mathrm{C}_{0} \mathrm{H}_{22} \mathrm{O}_{6}+6 \mathrm{O}_{2} \rightarrow 6 \mathrm{CO}_{2}+6 \mathrm{H}_{2} \mathrm{O} \text {. }
$$

If $h^{1}$ is the change in the manometer reading and $\mathrm{k}^{1} \mathrm{O}_{2}$ the flask constant for oxygen, then the volume of this gas taken up in respiration in the Warburg vessel with alkali in the center cup may, as in alternative 2 , be calculated as follows:

$$
\mu \mathrm{l} \mathrm{O}_{2}^{\text {resp }}=\mathrm{h}^{1} \times \mathrm{k}^{1} \mathrm{O}_{2} .
$$

From the formulae it is evident that carbon dioxide is formed not only in fermentation but also in respiration. The volume of the gas produced in the last process is obtained from the following expression:

$$
\mu \mathrm{l} \mathrm{CO}{ }_{2}^{\text {resp }}=\mu 1 \mathrm{O}_{2}^{\mathrm{resp}} \times \frac{\mathrm{n} \cdot}{2+\mathrm{n}}=\mathrm{h}^{1} \times \mathrm{k}^{1} \mathrm{O}_{2} \times \frac{\mathrm{n}}{2+\mathrm{n}} .
$$

The change in the manometer reading observed for the vessel without alkali in the center cup, $\mathrm{h}^{2}$, results from the decrease in pressure 
due to the uptake of oxygen in respiration, $\mathrm{h}^{2} \mathrm{a}$, and the increase in pressure due to the carbon dioxide formation in fermentation, $\mathrm{h}^{2}{ }_{\mathrm{b}}$, and in respiration $\mathrm{h}^{2} \mathrm{c}$. If $\mathrm{k}^{2} \mathrm{O}_{2}$ and $\mathrm{k}^{2} \mathrm{CO}_{2}$ are the flask constants for oxygen and carbon dioxide, respectively, these three quantities may be expressed as follows:

and

$$
\begin{gathered}
\mathrm{h}^{2} \mathrm{a}=\frac{\mu \mathrm{l} \mathrm{O} \mathrm{O}^{\text {resp }}}{\mathrm{k}^{2} \mathrm{O}_{2}}=\mathrm{h}^{1} \times \frac{\mathrm{k}^{1} \mathrm{O}_{2}}{\mathrm{k}^{2} \mathrm{O}_{2}}, \\
\mathrm{~h}^{2} \mathrm{~b}=\frac{\mu 1 \mathrm{CO}_{2}^{\text {ferm }}}{\mathrm{k}^{2} \mathrm{CO}_{2}}
\end{gathered}
$$

Thus:

$$
\mathrm{h}^{2}{ }_{\mathrm{c}}=\frac{\mu \mathrm{l} \mathrm{C \textrm {CO } _ { 2 }} \mathrm{resp}^{\mathrm{res}}}{\mathrm{k}^{2} \mathrm{CO}_{2}}=\frac{\mu 1 \mathrm{O}_{2} \text { resp }}{\mathrm{k}^{2} \mathrm{CO}_{2}} \times \frac{\mathrm{n}}{2+\mathrm{n}}=\mathrm{h}^{1} \times \frac{\mathrm{k}^{1} \mathrm{O}_{2}}{\mathrm{k}^{2} \mathrm{CO}_{2}} \times \frac{\mathrm{n}}{2+\mathrm{n}} .
$$

or

$$
\mathrm{h}^{2}=\mathrm{h}^{2} \mathrm{~b}+\mathrm{h}^{2} \mathrm{c}-\mathrm{h}^{2} \mathrm{a}=\frac{\mu \mathrm{l} \mathrm{CO} \mathrm{CO}_{2}{ }^{\mathrm{ferm}}}{\mathrm{k}^{2} \mathrm{CO}_{2}}+\frac{\mu \mathrm{lO} \mathrm{O}_{2}{ }^{\text {resp }}}{\mathrm{k}^{2} \mathrm{CO}_{2}} \times \frac{\mathrm{n}}{2+\mathrm{n}}-\frac{\mu \mathrm{IO} \mathrm{O}_{2}^{\text {resp }}}{\mathrm{k}^{2} \mathrm{O}_{2}}
$$

and

$$
\mathrm{h}^{2} \times \mathrm{k}^{2} \mathrm{CO}_{2}=\mu \mathrm{l} \mathrm{CO}_{2}^{\text {ferm }}+\mu \mathrm{l} \mathrm{O}_{2}^{\text {resp }} \times \frac{\mathrm{n}}{2+\mathrm{n}}-\mu \mathrm{l} \mathrm{O}_{2}^{\text {resp }} \times \frac{\mathrm{k}^{2} \mathrm{CO}_{2}}{\mathrm{k}^{2} \mathrm{O}_{2}}
$$

$$
\mu 1 \mathrm{CO}_{2}{ }^{\text {ferm }}=\mathrm{h}^{2} \times \mathrm{k}^{2} \mathrm{CO}_{2}+\mu \mathrm{l} \mathrm{O}_{2} \text { resp } \times\left(\frac{\mathrm{k}^{2} \mathrm{CO}_{2}}{\mathrm{k}^{2} \mathrm{O}_{3}}-\frac{\mathrm{n}}{2+\mathrm{n}}\right) .
$$

This expression may, on the assumptions made in alternative 3 , be used in calculating the actual volume of carbon dioxide produced in aerobic fermentation.

4. The yeast cells show on one hand fermentation, on the other hand respiration according to the formulae:

$$
\begin{aligned}
& \mathrm{C}_{6} \mathrm{H}_{12} \mathrm{O}_{6} \rightarrow 2 \mathrm{CO}_{2}+2 \mathrm{CH}_{3} \cdot \mathrm{CH}_{2} \mathrm{OH} \\
& \mathrm{C}_{6} \mathrm{H}_{12} \mathrm{O}_{6}+6 \mathrm{O}_{2} \rightarrow 6 \mathrm{CO}_{2}+6 \mathrm{H}_{2} \mathrm{O} .
\end{aligned}
$$

The end products of aerobic dissimilation are thus carbon dioxide, ethyl alcohol and water.

If $\mathrm{h}^{1}$ is the change of the manometer reading of the Warburg vessel with alkali in the center cup and $\mathrm{k}^{1} \mathrm{O}_{2}$ is the constant of the vessel for oxygen, then the amount of this gas absorbed in respiration is obtained as follows:

$$
\mu \mathrm{I} \mathrm{O}_{2} \text { resp }=\mathrm{h}^{1} \times \mathrm{k}^{1} \mathrm{O}_{2} .
$$

From the formulae it appears that carbon dioxide is produced in respiration as well as in fermentation. The volume of this gas formed in the first process is equal to the volume of oxygen taken up:

$$
\mu \mathrm{l} \mathrm{CO}{ }_{2}^{\text {resp }}=\mu 1 \mathrm{O}_{2}^{\text {resp }}=h^{1} \times k^{1} \mathrm{O}_{2} .
$$


The change in the manometer reading found for the flask without alkali in the center cup, $\mathrm{h}^{2}$, results, as in alternative 3 , from the decrease in pressure due to oxygen uptake in respiration, $\mathrm{h}^{2}{ }^{2}$, and the increase in pressure due to carbon dioxide production in fermentation, $\mathrm{h}^{2} \mathrm{~b}$, and in respiration, $\mathrm{h}_{\mathrm{c}}^{2}$. If $\mathrm{k}^{2} \mathrm{O}_{2}$ and $\mathrm{k}^{2} \mathrm{CO}_{2}$ are the constants of the flask concerned for oxygen and carbon dioxide, respectively, we get:

$$
\begin{gathered}
\mathrm{h}^{2} \mathrm{a}=\frac{\mu 1 \mathrm{O}_{2}^{\text {resp }}}{\mathrm{k}^{2} \mathrm{O}_{2}}=\mathrm{h}^{1} \times \frac{\mathrm{k}^{1} \mathrm{O}_{2}}{\mathrm{k}^{2} \mathrm{O}_{2}} \\
\mathrm{~h}^{2} \mathrm{~b}=\frac{\mu 1 \mathrm{CO}_{2}{ }^{\text {erm }}}{\mathrm{k}^{2} \mathrm{CO}_{\mathrm{a}}}
\end{gathered}
$$

and

Thus:

$$
\mathrm{h}^{2} \mathrm{c}=\frac{\mu \mathrm{l} \mathrm{CO}{ }_{2}^{\mathrm{resp}}}{\mathrm{k}^{2} \mathrm{CO}_{2}}=\frac{\mu \mathrm{l} \mathrm{O} \mathrm{O}_{2}^{\mathrm{resp}}}{\mathrm{k}^{2} \mathrm{CO}_{3}}=\mathrm{h}^{1} \times \frac{\mathrm{k}^{\mathrm{1}} \mathrm{O}_{2}}{\mathrm{k}^{2} \mathrm{CO}_{3}} .
$$

or

$$
\mathrm{h}^{2}=\mathrm{h}^{2} \mathrm{~b}+\mathrm{h}^{2} \mathrm{c}-\mathrm{h}^{2} \mathrm{a}=\frac{\mu 1 \mathrm{CO}_{3}^{\text {ferm }}}{\mathrm{k}^{2} \mathrm{CO}_{3}}+\frac{\mu \mathrm{l} \mathrm{O}_{2}^{\text {resp }}}{\mathrm{k}^{2} \mathrm{CO}_{2}}-\frac{\mu \mathrm{lO} \mathrm{O}_{2} \text { resp }}{\mathrm{k}^{2} \mathrm{O}_{2}}
$$

and

$$
\mathrm{h}^{2} \times \mathrm{k}^{2} \mathrm{CO}_{3}=\mu \mathrm{l} \mathrm{C \textrm {CO } _ { 2 }}{ }^{\mathrm{Rerm}}+\mu \mathrm{lO} \mathrm{O}_{2}^{\mathrm{resp}}-\mu \mathrm{l} \mathrm{O}_{2}^{\mathrm{resp}} \times \frac{\mathrm{k}^{2} \mathrm{CO}_{2}}{\mathrm{k}^{2} \mathrm{O}_{2}}
$$

$$
\mu \mathrm{l} \mathrm{CO}{ }_{2}^{\text {ferm }}=h^{2} \times \mathrm{k}^{2} \mathrm{CO}_{3}+\mu \mathrm{l} \mathrm{O} \mathrm{O}_{2}^{\text {resp }} \times\left(\frac{\mathrm{k}^{2} \mathrm{CO}_{2}}{\mathrm{k}^{2} \mathrm{O}_{2}}-1\right) .
$$

On the assumptions made in alternative 4 , this expression may be applied in calculating the actual amount of carbon dioxide formed in aerobic fermentation. Under the experimental conditions applied the value of the quotient between the flask constant for carbon dioxide and that for oxygen varies from 1.072 to 1.083 . Hence the values for the oxygen uptake in respiration have to be multiplied by a term ranging from 0.072 to 0.083 . Consequently, the correction to be applied for respiration in most cases is comparatively small or even negligible (cf. Table 7).

\section{REsUlts.}

The results obtained in measuring the rate of fermentation in air and in oxygen-free nitrogen and calculating the aerobic fermentation according to formula 1 , i.e. without any correction for an oxygen uptake, will be seen in Tables 1, 2 and 3 . As a matter of fact, manometer readings were made at intervals of 15 minutes in all experi- 


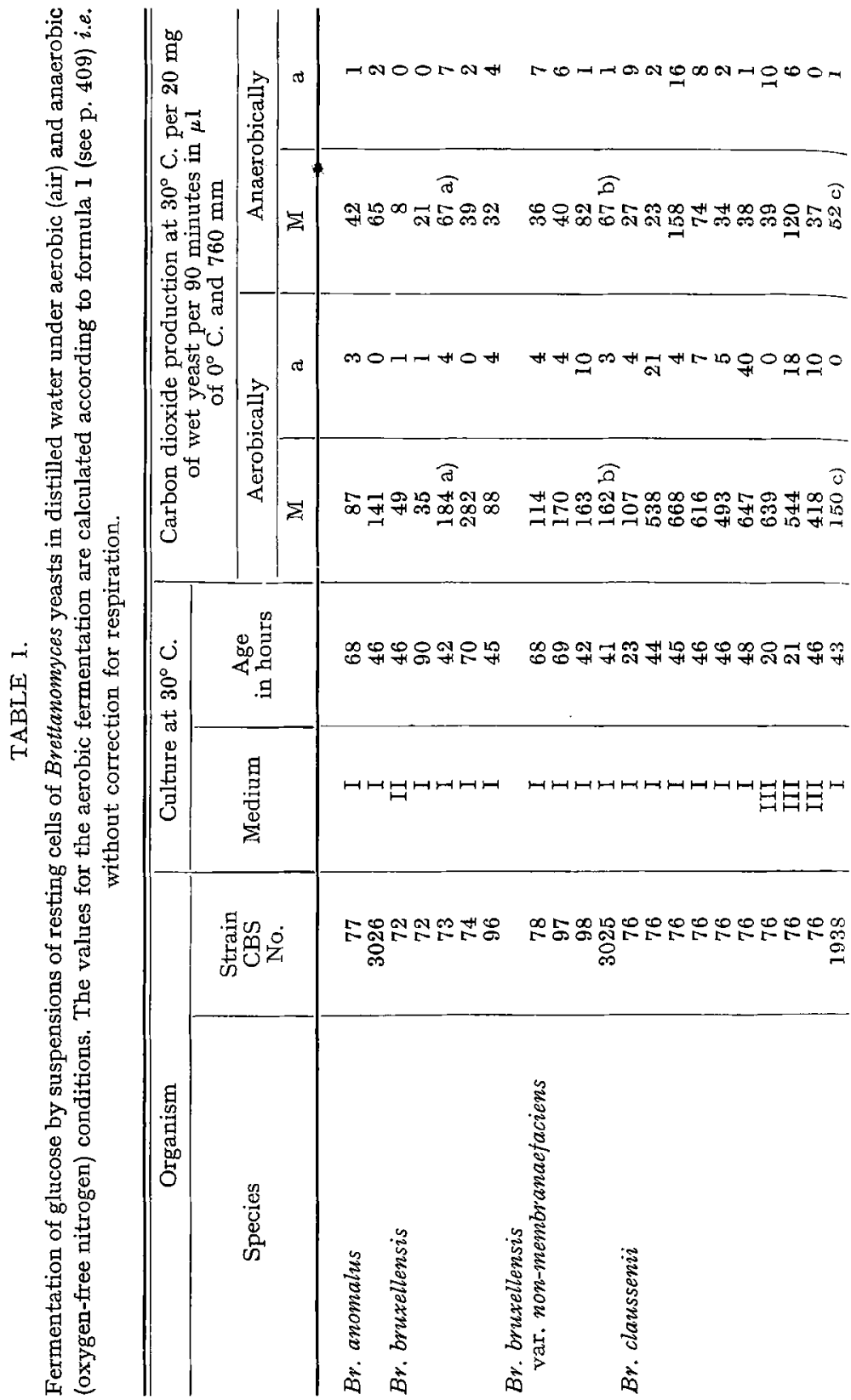




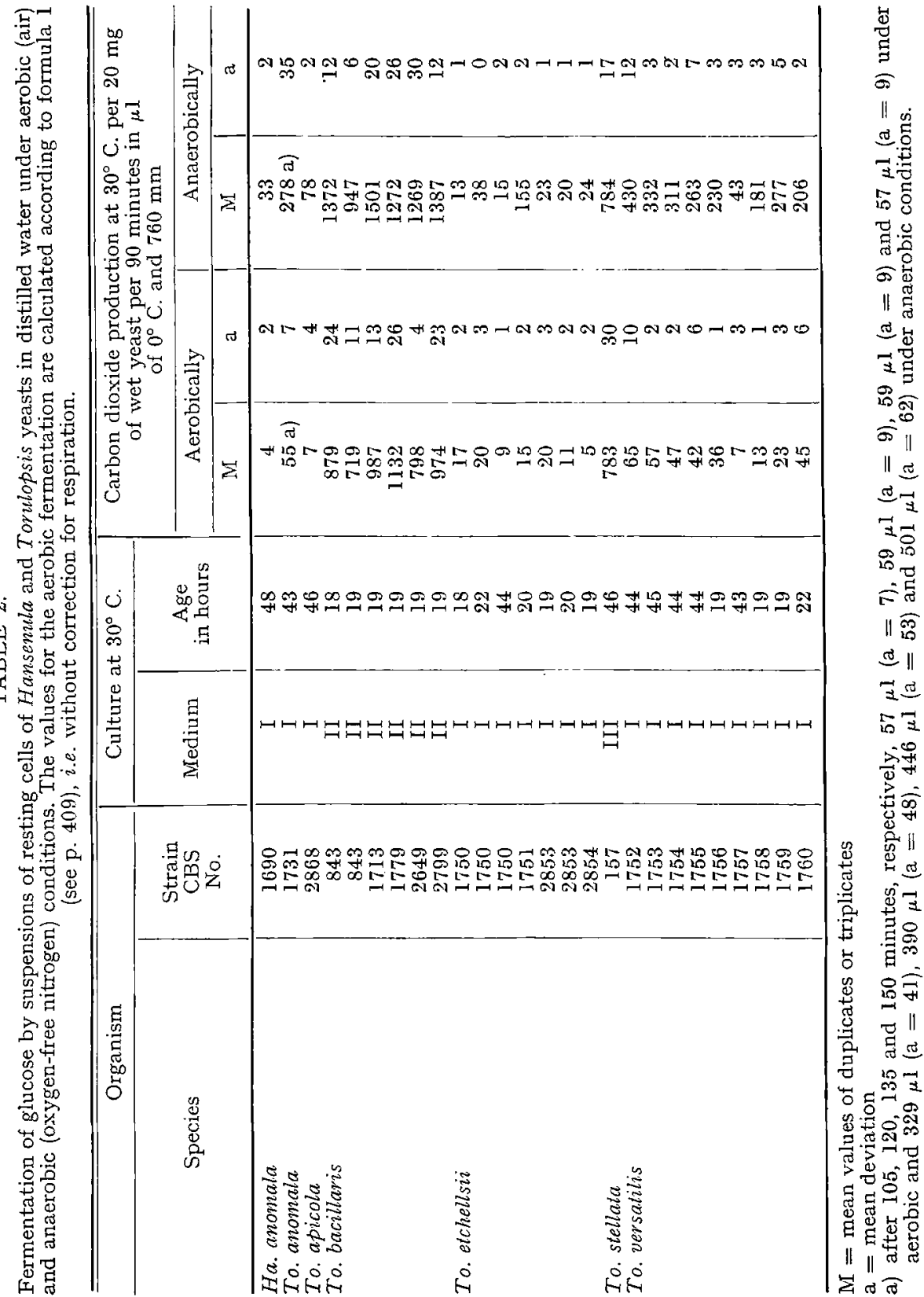




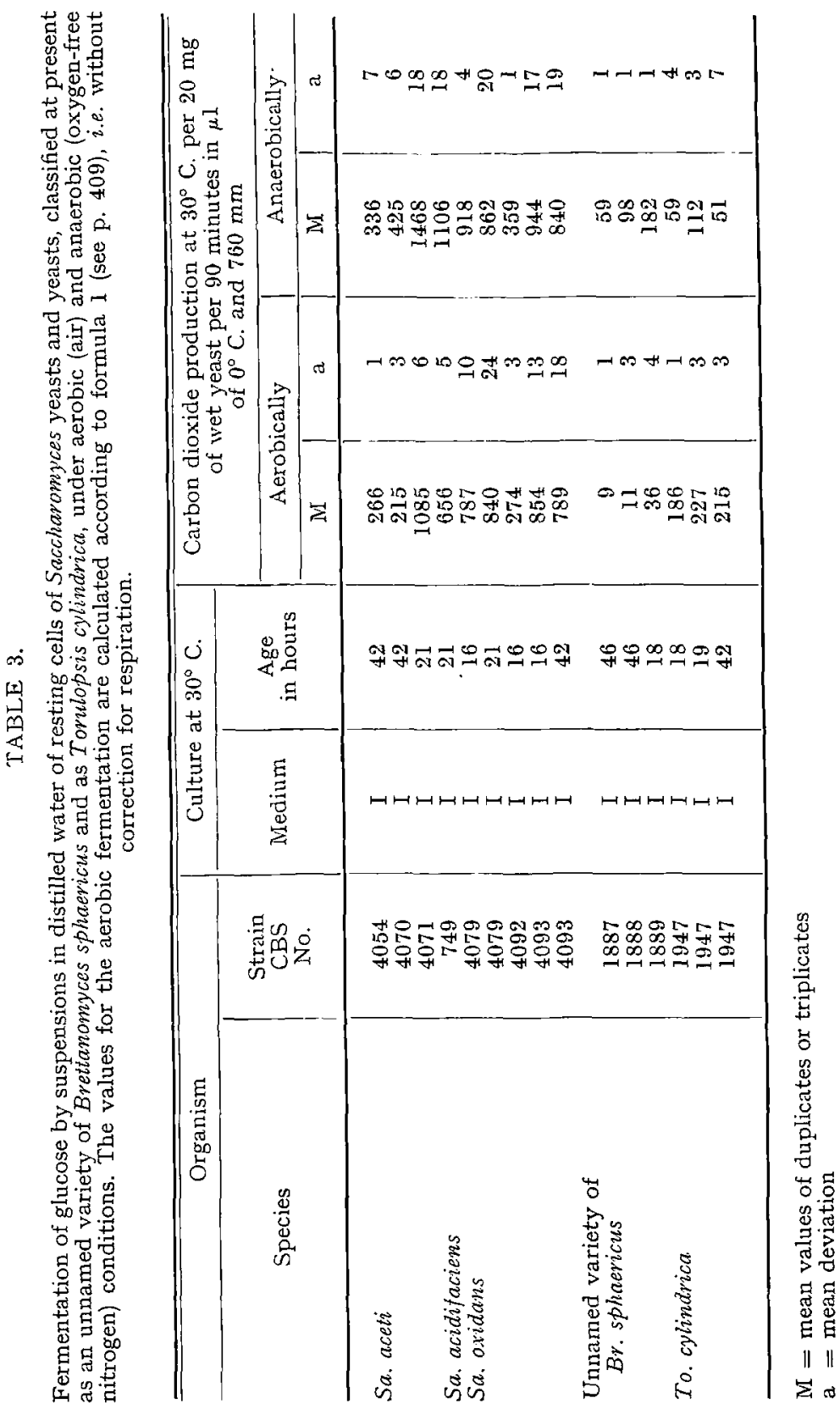


ments, but from considerations of space and clearness in most cases only the values observed after 90 minutes are listed. In a few cases the fermentation was measured even over longer periods than 90 minutes. The values thus obtained are also recorded in the tables mentioned.

From the results presented in Table 1 it is evident that all 22 strains of the Brettanomyces species so far tested show a negative Pasteur effect irrespective of the medium used for growing the cells concerned. Furthermore, it is obvious that, on comparing the rate of anaerobic fermentation with the corresponding values for the aerobic process calculated according to formula 1, i.e. without consideration of the oxygen uptake, mostly no negative Pasteur effect is found in cells harvested from 41-46 hours old cultures of the strains CBS 1941, CBS 1942 and CBS 1943 of Br. vini, whereas in cells from 22 hours old cultures of the same strains a typical effect may be observed.

It may be added that in the cells manifesting a negative Pasteur effect after a period of 90 or more minutes this effect sets in immediately after addition of the glucose solution to the cell suspensions, the fermentation curve obtained under aerobic conditions thus from the very beginning of the sugar dissimilation diverging from that observed under anaerobic conditions.

For the cells from 41 hours old cultures of $\mathrm{Br}$. vini, strain CBS 1941, which do not show any negative Pasteur effect, the fermentation curves recorded in air and in oxygen-free nitrogen, respectively, are practically identical up to 90 minutes, whereas the cells from 41, 46 and 42 hours old cultures of $B r$. vini, strains CBS 1942, CBS 1942 and CBS 1943, respectively, show a negative Pasteur effect up to 60,75 and 60 minutes. Subsequently, however, this effect disappears, and the dissimilation curves cross one another at about 67,85 and 65 minutes, respectively, the curves for the cell suspensions in air showing a decrease and those for the suspensions in oxygen-free nitrogen an increase in the slope with time.

From the data given in Table 2 it is obvious that no negative Pasteur effect may be demonstrated in Hansenula anomala and the 20 strains of the six Torulopsis species examined, on comparing the amounts of carbon dioxide formed under anaerobic conditions with those recorded for aerobic conditions without correction for the respiration. It may be mentioned that in these experiments, with a few exceptions, all manometer readings made for the anaerobic cell 
suspensions are higher than the corresponding readings for the aerobic suspensions, the curve for anaerobic conditions hence from the very beginning of the glucose dissimilation diverging from that obtained for aerobic conditions. In a few Torulopsis strains the curves recorded for the anaerobic and aerobic sugar dissimilation, respectively, are practically identical.

The results listed in Table 3 show conclusively that, on calculating the aerobic carbon dioxide formation according to formula 1 and hence neglecting the respiration, no negative Pasteur effect may be observed in the Saccharomyces species tested or in the unnamed variety of Brettanomyces sphaericus, whereas the cells from 18-42 hours old cultures of Torulopsis cylindrica show such an effect of the same order of magnitude as found in typical Brettanomyces strains. It may be added that the experimental results are clear-cut, the curves for the aerobic and anaerobic glucose dissimilation diverging promptly from one another from the addition of the sugar on, or in two cases, viz. in the cells of the strains CBS 4079 and CBS 4093 of Sa. oxidans from 21 and 42 hours old cultures, respectively, showing approximately the same course.

Summarizing the results presented in Tables 1, 2 and 3, we may state that, if the oxygen uptake in respiration is not taken into account in calculating the amounts of carbon dioxide formed in aerobic fermentation, then a negative Pasteur effect can be proved only in the true Brettanomyces species, and in the strain of Torulopsis cylindrica examined. In all other yeast strains tested, classified as Hansemula, Torulopsis and Saccharomyces species, as well as in the unnamed variety of Brettanomyces sphaericus, such an effect cannot be demonstrated on applying formula 1 in calculating the formation of carbon dioxide in aerobic fermentation.

The actual magnitude of the negative Pasteur effect established qualitatively by using formula 1 in estimating the aerobic fermentation may be found by determining the corresponding oxygen uptake in respiration and applying one of the formulae 2, 3 and 4 for calculating the proper correction. The choice of formula has, of course, to be based on a careful examination of the type of oxybiontic sugar dissimilation involved: Experimental work on this problem is in progress in our laboratory. Attention may here be called to the fact that the actual values for the aerobic fermentation are even higher than the values obtained by calculation according to formula 1 . On the basis of the data presented in Tables 1 and 3 
therefore only minimum values for the magnitude of the negative Pasteur effect in the yeasts concerned may be estimated.

Furthermore, it is a priori quite possible that yeast strains in which no negative Pasteur effect is found on calculating the aerobic fermentation without correction for the respiration, nevertheless in reality possess this effect. Such a "masking" of the negative Pasteur effect is to be expected particularly in yeasts with a comparatively high oxygen uptake accompanied by an incomplete oxidation of the ethyl alcohol formed in fermentation.

In order to get some preliminary information about the order of magnitude of the corrections to be applied according to formulae 2, 3 and 4 because of respiration, the oxygen uptake of the yeasts was measured using cells from cultures of approximately the same age as in the determination of the carbon dioxide formation. Some results are listed in Tables 4, 5 and 6 . As was to be expected, the yeasts behave in different ways as regards the dependence of the respiration on the age of the cultures concerned, the oxygen uptake in some strains being comparatively constant, in other strains increasing or decreasing with an increase in the culture age. Some yeast strains showed a high reproducibility as regards the respiration in cells from cultures of the same age, whereas in other strains a strong variation was observed in the rate of oxygen uptake of such cells from one experiment to another. In some species approximately the same respiratory activity was observed for the different strains tested, whereas in other species great differences were found between strains as regards the rate of the oxygen uptake even on comparing cells from cultures of about the same age. Anyhow, it is evident from the values listed in Tables 4, 5 and 6 that the respiration in several yeasts is of such an order of magnitude that a masking of an eventual negative Pasteur effect cannot a priori be excluded or even seems quite possible. In view of the strong variation in respiratory activity mentioned the oxygen uptake in respiration and the formation of carbon dioxide in anaerobic fermentation as well as the mixed sugar dissimilation under aerobic conditions were measured using portions of one and the same yeast suspension in air in Warburg vessels with alkali in the center cup, and in oxygenfree nitrogen and air, respectively, in vessels without alkali. We are, of course, fully aware of the fact that this "direct method" for measuring the aerobic glucose dissimilation gives correct results only on the condition that the metabolic processes involved go on 


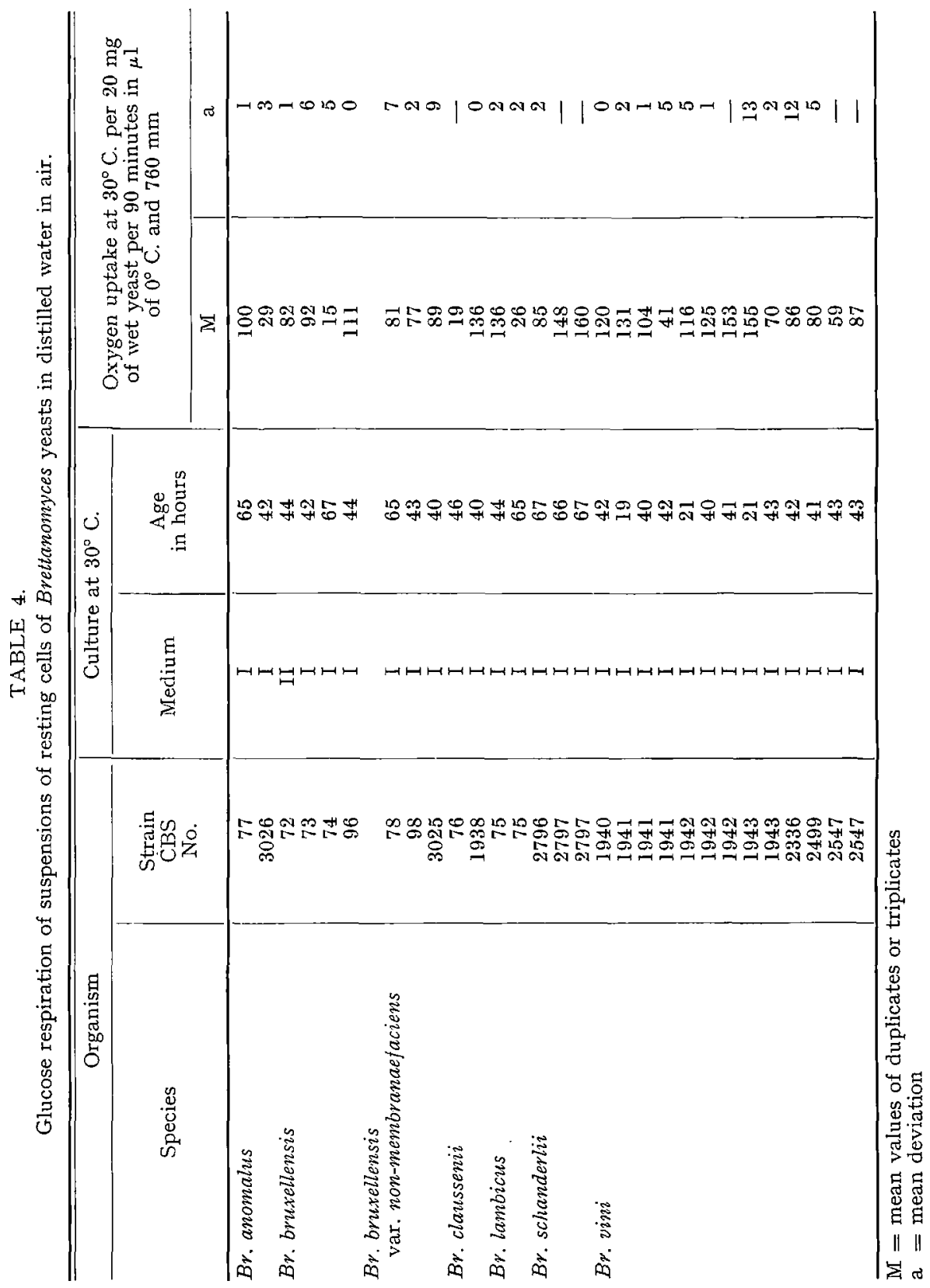


T. Wikén, W. A. Scheffers and A. J. M. Verhaar,

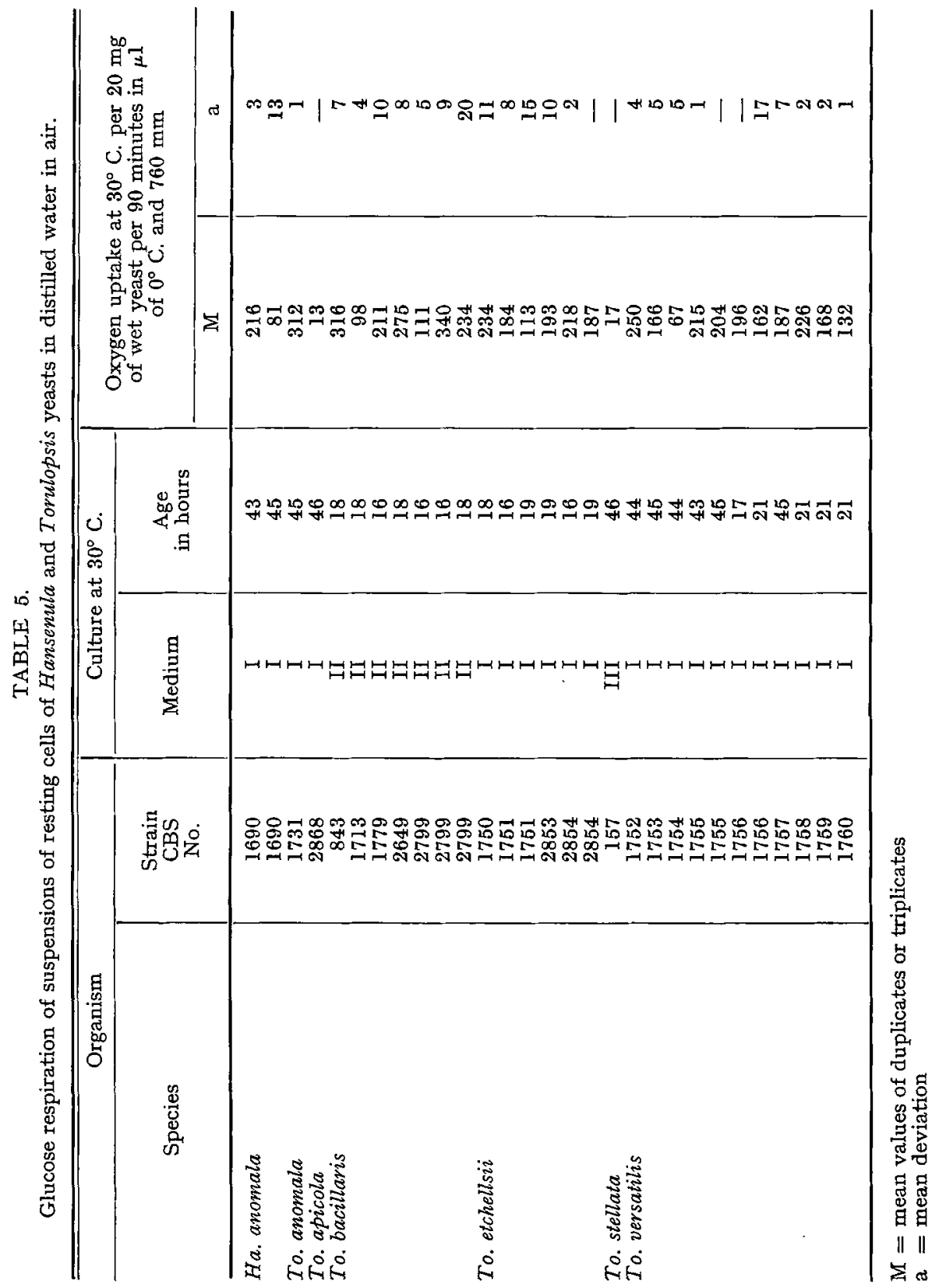




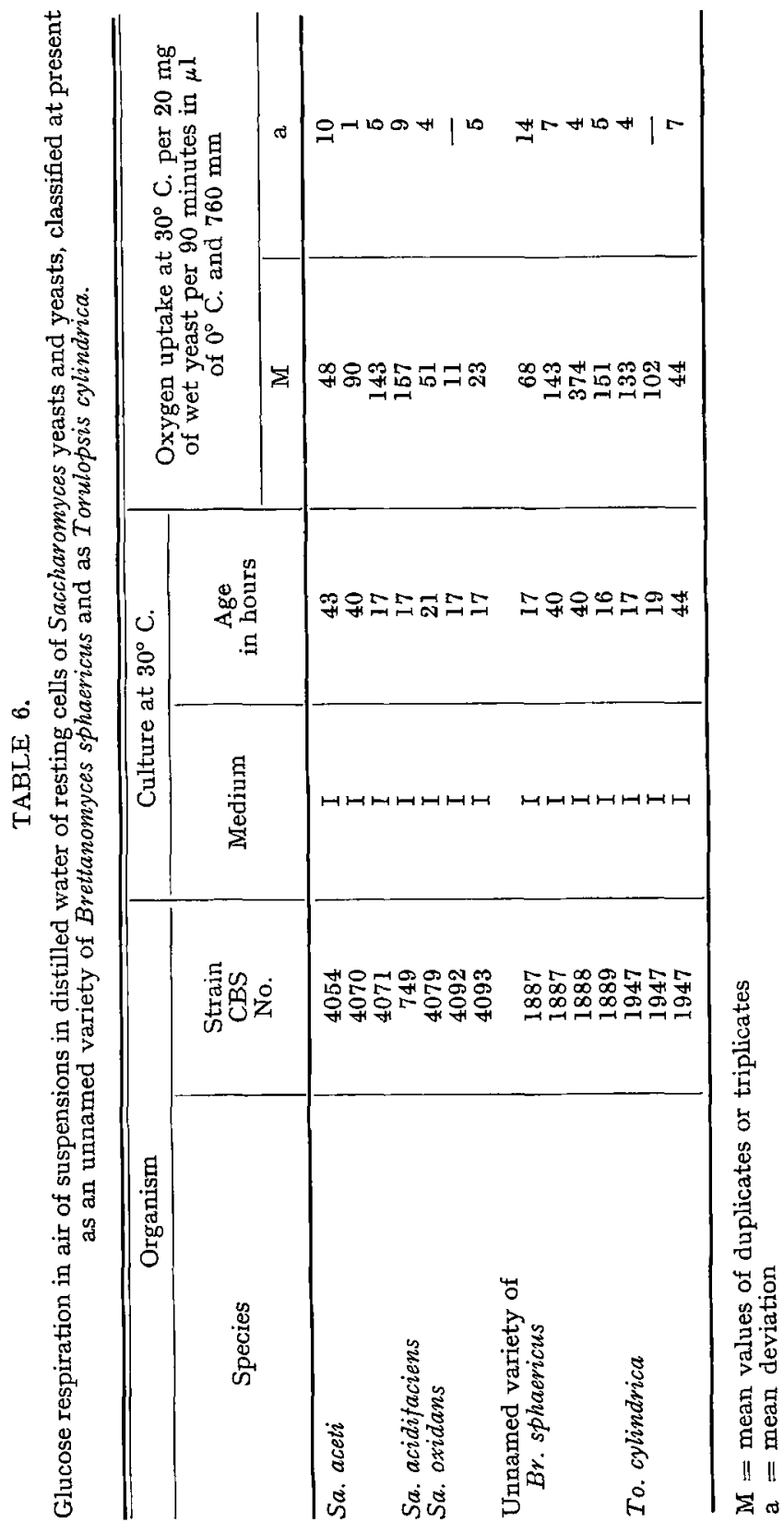


T. Wikén, W. A. Scheffers and A. J. M. Verhaar,

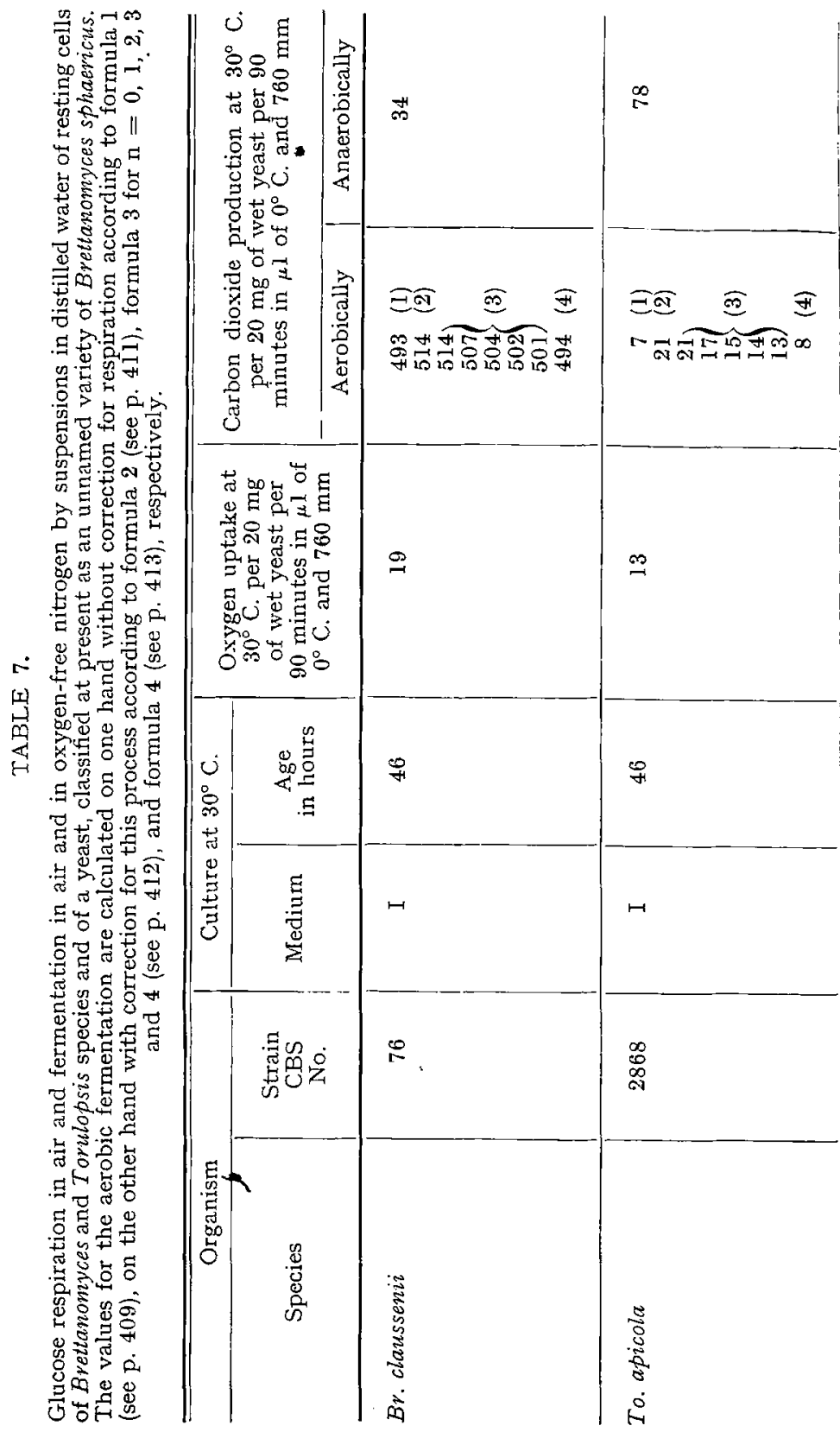




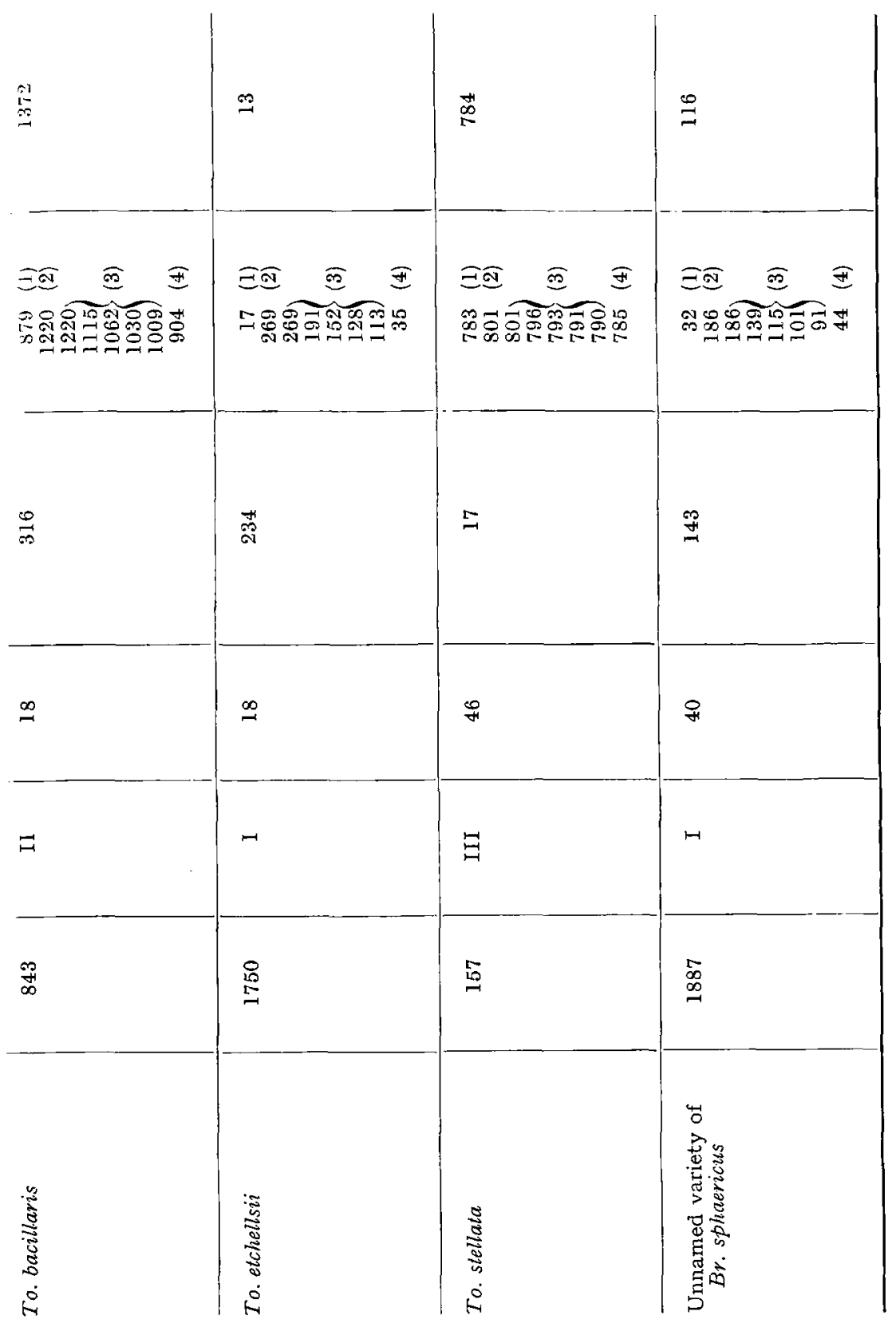


at the same rate irrespective of whether carbon dioxide is present in the gas phase above the yeast suspensions or not. Some results obtained in these experiments are presented in Table 7 .

On comparing the values given in Table 7 for the amounts of carbon dioxide formed in anaerobic fermentation with those found for the aerobic fermentation by calculation according to formulae 1 , 2, 3 and 4 it will be seen that the magnitude of the negative Pasteur effect in strain CBS 76 of Brettanomyces claussenii does not change very much on considering the respiration, the oxygen uptake being a rather small one and the carbon dioxide volume produced in aerobic fermentation varying from a minimum value of $493 \mu 1$ (formula 1; without correction for respiration) to a maximum value of $514 \mu 1$ (formulae 2 and 3 ; with correction for respiration; $\mathrm{n}=0$ in formula 3). Furthermore, it is evident from Table 7 that no negative Pasteur effect may be found in strain CBS 2868 of Torulopsis apicola and strain CBS 843 of To. bacillavis even on application of a maximum correction for the oxygen uptake, the values for the anaerobic fermentation being $78 \mu 1$ and $1372 \mu \mathrm{l}$, and those for the aerobic fermentation varying within the ranges of $7-21 \mu 1$ and $879-1220 \mu 1$ of carbon dioxide, respectively. In strain CBS 157 of To. stellata the values for the aerobic fermentation obtained on applying corrections for respiration according to formulae 2 and 3 , viz. 790-801 $\mu 1$, are somewhat higher than the corresponding value for the anaerobic fermentation, viz. $784 \mu 1$, but the differences are undoubtedly too small to be considered as significant, the strain hence probably lacking a negative Pasteur effect. In the unnamed variety of Brettanomyces sphaericus, strain CBS 1887, a comparatively great difference is obtained between the rate of the aerobic fermentation and that of the anaerobic process on the assumption that it is allowed to apply a maximum correction for the oxygen uptake, the value calculated according to formulae 3 (for $n=0$ ) and 2 for the amount of carbon dioxide formed in aerobic fermentation being $186 \mu 1$, while the corresponding value for anaerobic conditions is only $116 \mu 1$. In view of the fact, however, that on calculation using the other formulae or other values for $n$, respectively, values for the aerobic fermentation are obtained which are definitely smaller than or practically identical with or, considering the limits of experimental error, not clearly different from the value directly determined for the anaerobic process (32 and $44 \mu 1 ; 115 \mu 1$; 91,101 and $139 \mu 1$; as compared to $116 \mu 1$ ), we would prefer to 
leave the question whether or not a masked negative Pasteur effect exists in strain CBS 1887 of the unnamed variety of Br. sphaericus open until sufficient information about the nature of the oxybiontic glucose dissimilation of this strain is available.

Finally, it is evident from Table 7 that a masked negative Pasteur effect very probably exists in strain CBS 1750 of Torulopsis etchellsii. The uncorrected value for the aerobic fermentation, viz. $17 \mu 1$, is practically identical with the value for the anaerobic fermentation, viz. $13 \mu 1$, while the latter value is throughout surpassed by the values for the aerobic fermentation found on correction for the respiration according to formulae 2,3 and 4, viz. $269 \mu 1$, $113,128,152,191$ and $269 \mu 1$, and $35 \mu 1$, respectively.

It may be mentioned that in all experiments presented in Table 7 manometer readings were made at intervals of 15 minutes. The values for a fermentation and respiration period of 90 minutes, listed in the table, fall throughout on smooth curves.

\section{Discussion and Conclusions.}

A negative Pasteur effect in the sense of an inhibition of the rate of the alcoholic fermentation under anaerobic conditions (in oxygenfree nitrogen) and a stimulation of this process in presence of molecular oxygen (in air) was conclusively demonstrated in two strains of Brettanomyces anomalus, four strains of $\mathrm{Br}$. bruxellensis, four strains of Br. bruxellensis var. non-membranaefaciens, two strains of $B r$. claussenii, one strain of $B r$. lambicus, two strains of $B r$. schanderlii, and seven strains of Br. vini, i.e. in all Brettanomyces strains so far tested. It has to be stressed that these strains represent organisms which have been subcultured on ordinary laboratory media for long periods of time. In view of the variation from type occurring more or less commonly in microbes on keeping them in artificial culture no conclusions may be drawn about the presence or absence of such an effect in freshly isolated Brettanomyces strains.

In the Brettanomyces strains mentioned the negative Pasteur effect can be proven even in calculating the amounts of carbon dioxide formed in aerobic fermentation without correction for an eventual sinultaneous uptake of molecular oxygen and the more or less equivalent formation of carbon dioxide in respiration. This holds for the Brettanomyces strains with a comparatively high respiration ( $\geqq 75-100 \mu 1$ of $\mathrm{O}_{2}$ per $20 \mathrm{mg}$ of wet yeast per 90 
minutes) as well as for those with a low respiration (@ $15-30 \mu 1$ of $\mathrm{O}_{2}$ per $20 \mathrm{mg}$ of wet yeast per 90 minutes).

In some strains of Brettanomyces vini the negative Pasteur effect may be demonstrated only in cells from young cultures on calculating the aerobic fermentation without consideration of the oxygen uptake.

It may be added that the actual values for the negative Pasteur effect obtained on correction for the respiration will be even greater than the values found without correction. This will be the case in particular when the oxygen taken up is used in incomplete oxidation without formation of carbon dioxide, e.g. in conversion of the ethyl alcohol, produced in fermentation, to acetic acid.

In addition, a negative Pasteur effect could be established in one strain of Tornlopsis cylindrica even without applying any correction for the molecular oxygen taken up in respiration $(\cong 40-135 \mu 1$ per $20 \mathrm{mg}$ of wet yeast per 90 minutes).

In all other yeasts so far examined, viz. one strain of Hansenula anomala, one strain of Torulopsis anomala, one strain of To. apicola, five strains of To. bacillaris, four strains of To. etchellsii, one strain of To. stellata, nine strains of To. versatilis, three strains of Saccharomyces aceti, one strain of $S a$ acidilaciens, three strains of $S a$. oxidans, and three strains of an unnamed variety of Brettanomyces sphaericus (classified at present as Torulopsis etchellsii), no negative Pasteur effect could be observed on estimating the aerobic fermentation without correction for respiration. Some of these yeast strains are characterized by a very low, other strains by a moderate to high respiration, the oxygen uptake varying between 11 and $374 \mu 1$ of $\mathrm{O}_{2}$ per $20 \mathrm{mg}$ of wet yeast per 90 minutes. It has to be emphasized that most of the strains are included in yeasts which earlier were described as Brettanomyces species or were suspected to be closely related to or even belong to this genus, while other strains are similar to Brettanomyces yeasts in possessing the capacity to form acetic acid.

In some of the yeast stcains which do not show any negative Pasteur effect on calculating the aerobic fermentation without correction for the respiration, the anaerobic fermentation and the mixed aerobic dissimilation (aerobic fermentation + respiration) of glucose was examined using one and the same cell material. On application of a correction for the oxygen uptake in respiration in calculating the carbon dioxide formed in aerobic fermentation according to three alternatives no negative Pasteur effect was found 
in strains of yeasts like Tortlopsis apicola, To. bacillaris and To. stellata. In a strain of the unnamed variety of $B r$. sphaericus such an effect was obtained only on applying the maximum correction for respiration. Hence, a decisive conclusion as regards the existence of a negative Pasteur effect in this yeast has to be postponed until a careful examination of its oxybiontic sugar dissimilation has proven that such a correction actually is legitimate. In a strain of $T o$. etchellsii, finally, a negative Pasteur effect was observed on correction for the oxygen uptake according to all alternatives so far considered. On neglecting this correction the effect is being masked due to the uptake of molecular oxygen.

On basis of the above findings the following three groups of yeasts may be distinguished:

1) yeasts possessing a negative Pasteur effect which may be observed by manometric techniques even without application of any correction for the oxygen uptake and carbon dioxide formation in respiration; this group includes all Brettanomyces strains so far tested, and, in addition, a strain of Torulopsis cylindrica;

2) yeasts possessing a negative Pasteur effect which is masked by the uptake of molecular oxygen in respiration, and, hence, can be proved by manometric techniques only on application of the proper correction for respiration; strains of Torulopsis etchellsii are representatives of this group;

3) yeasts lacking a negative Pasteur effect.

As will be reported in detail elsewhere, the negative Pasteur effect in the Brettanomyces yeasts may be demonstrated not only in cell suspensions in distilled water, but also in suspensions prepared with phosphate buffer or with solutions of mixtures of organic acids and their sodium or potassium salts, e.g. citric acid-citrate, DLmalic acid-malate, fumaric acid-fumarate, succinic acid-succinate, D-tartaric acid-tartrate, malonic acid-malonate, and acetic acidacetate mixtures. Now WIKÉN and co-workers (1953b, 1954a and b, 1955a and b, 1957, 1958, 1959, 1961) and PFENNIG and WIKÉN (1960a and $b$ ) have demonstrated the existence of a negative Pasteur effect in intact cells of strains of Saccharomyces carlsbergensis, Sa. cerevisiae, and $S a$. wvarwn. This effect, however, is caused specifically by the succinic acid-succinate system, whereas no effect at all or only a minute one is obtained in distilled water, phosphate buffer or solutions of mixtures of other organic acids and their salts. Hence, an additional group of yeasts exists, viz. 
4) yeasts showing a negative Pasteur effect only under particular environmental conditions, e.g. in suspensions of resting cells in succinic acid-succinate solutions of definite concentrations and $\mathrm{pH}$ values; in the strains of the Saccharomyces species mentioned this effect appears only in cells from very young cultures.

In view of the results described in the present paper it seems quite reasonable to ponder the question whether or not the presence or absence of a negative Pasteur effect could be used as a criterion in classification of yeasts. In this connection it has to be considered that even minute amounts of molecular oxygen may have a stimulating effect on the rate of alcoholic fermentation. By way of example, Schefrers (1961) mentions that a marked increase in the rate of this process is observed in Bretlanomyces claussenii in presence of 0.1 per cent of oxygen in the gas phase. Still earlier WIKÉN and RICHARD (1955b) have shown that in the Fendant strain of Saccharomyces carlsbergensis a stimulation sets in on supplementing the gas phase above the cell suspensions with 0.005 per cent by volume of molecular oxygen. Under the experimental conditions applied this means that even amounts of only $2.5-3.0 \mu 1$ of oxygen, present in the gas phase, are active per $300 \mathrm{mg}$ of wet yeast or $60 \mathrm{mg}$ of yeast dry substance, corresponding on a weight basis to ratios of about $1-1.5: 100,000$ and $1-1.5: 20,000$, respectively. Undoubtedly it is a matter of course that the expediency and legitimacy of using Einhorn or Durham tubes without definitely securing anaerobiosis and aerobiosis in testing yeasts for their ability to ferment different sugars should be the subject of a careful re-examination. Before applying the presence or absence of a negative Pasteur effect as a characteristic in yeast taxonomy critical fermentation tests under on one hand strictly anaerobic, on the other hand strictly aerobic conditions should be carried out with a great number of yeasts belonging to different genera. Work along these lines is now in progress in our laboratory.

For the moment the fact that all Bretlanomyces strains so far tested possess a negative Pasteur effect which may be proven even without applying any correction for respiration, and that the yeasts at present brought to the genera Hansenula and Torulopsis but earlier described as Brettanomyces species or suspected to be closely related or even belong to this genus, lack such a non-masked effect, may undoubtedly be taken as evidence in support of removing these yeasts from the genus Brettanomyces. 
The fact that the strain of Torulopsis cylindrica Walters possesses a marked non-masked negative Pasteur effect has led to a re-examination of the systematic position of this yeast. The results will be published elsewhere before long.

The existence of a negative Pasteur effect in the sense described in the present paper is of considerable interest in view of the classical conception of the alcoholic fermentation in yeast as an anoxybiontic process which may take place under strictly anaerobic conditions. Custers (1940) as well as van Der WaLT and van Kerken (1959b) have shown that the anaerobic or "micro-aerobic" glucose dissimilation in Brettanomyces clanssenii is a normal alcoholic fermentation yielding equimolar amounts of ethyl alcohol and carbon dioxide, and, hence, occurring without consumption of any molecular oxygen. Notwithstanding this fact the alcoholic fermentation in this yeast takes place at a high rate only under aerobic conditions or, under anaerobic conditions, on external addition of oxidized coenzyme I or certain carbonyl compounds like acetaldehyde, acetone and pyruvic acid, which may replace molecular oxygen as hydrogen acceptors (SCHEFFERs, 1961). The molecular oxygen seems to stimulate the anoxybiontic process by partially re-oxidizing coenzyme I and possibly also other enzyme components which, under the experimental conditions applied, have been reduced too far (ct. Custers, 1940; Kluyver and Custers, 1940; Wrkén and Richard, 1953b, 1954a and b, 1955a and b; PFENNIG and WIKÉN, 1960a and b).

\section{Sum mary.}

The present paper deals with the "negative Pasteur effect" in yeasts, i.e. the inhibition of the alcoholic fermentation under anaerobic conditions and its stimulation in presence of elementary molecular oxygen. This effect was conclusively demonstrated in all Brettanomyces strains tested. In three strains of $B r$. vini, including one strain recently reclassified by VAN DER WALT and VAN KERKEN as Br. intermedius, mostly no negative Pasteur effect was found in cells harvested from comparatively old cultures, whereas in cells from young cultures a typical effect was obtained.

In addition, a negative Pasteur effect was established in Torulopsis cylindrica.

In examining a number of yeast strains at present classified as species of the genera Torulopsis, Saccharomyces and Hansenula no 
negative Pasteur effect was observed on calculating the aerobic fermentation without correction for respiration. However, the possibility exists that some of these strains possess a "masked negative Pasteur effect", i.e. an effect which may be proven only by applying an appropriate correction for respiration.

All tests were performed on suspensions of resting cells of the yeasts concerned in distilled water.

The taxonomic implications of the results are discussed.

$$
\text { A c knowledgements. }
$$

We are greatly indebted to the Delfts Hogeschoolfonds and to the Netherlands Organization for Pure Research (Z.W.O.) for grants supporting this work. Furthermore, we wish to thank Miss W. CH. SLOoff and Mrs N. J. W. KREGER-VAN RIJ for valuable discussions.

$$
\text { References. }
$$

BEDFORD, C. L. 1942. Mycologia 34, 628.

Bernhauler, K. 1939. Gärungschenisches Praktikum. Julius Springer, Berlin. Burk, D. 1939. Cold Spring Harbor Symp. Quant. Biol. 7, 420.

Ciba Foundation Symposium on the Regulation of Cell Metabolism. 1959. Ed. by Wolstenholme and O'Connor. J. \& A. Churchill Ltd., London.

Custirs, M. Тн. J. 1940. Onderzoekingen over het gistgeslacht Bvettanomyces. Thesis, Delft.

Etchelds, J. L. and Bell, Th. A. 1950. Farlowia 4, 87.

Etchelis, J. L. and BeLl, TH. A. 1952. Farlowia 4, 249.

Fisser, L. F. 1924. J. Amer. Chem. Soc. 46, 2639.

HAJSIG, M. 1958. Antonie van Leeuwenhoek 24, 18.

Kuuyver, A. J. 1924. Chem. Weekblad 21, 266.

Kluyver, A. J. and Donker, H. J. L. 1925. Proceed. Royal Acad. Sci. Amsterdam 28, 297, 605.

Kiuyver, A. J. and Donker, H. J. L. 1926. Chem. Zelle u. Gewebe 13, 134. Kroemer, $\mathrm{K}$. and Krumbrolz, G. 1931. Arch. Mikrobiol. 2, 352.

KRUmbHolz, G. 1931. Arch. Mikrobiol. 2, 411, 601.

KÜster, E. 1921. Anleitung zur Kultur der Mikroorganismen. B. G. Teubner, Leipzig \& Berlin.

LipMANN, F. 1933. Biochem. Zeitschr. 265, 133.

Lipmann, F. I934. Biochem. Beitschr. 268, 205.

Ltpmann, F. 1942. Pasteur Effect. In "A Symposium on Respiratory Enzymes", p. 48. The University of Wisconsin Press, Madison, Wis.

Lodder, J. and Kreger-Van RIJ, N. J. W. 1952. The Yeasts - A Taxonomic Study. North-Holland Publishing Co., Amsterdam.

McBee, R. H., Lamanin, C. and Weres, O. B. 1955. Bact. Rev. 19, 45.

Metzger, H. and Müller, E. 1959. Arbeiten unter Ausschluss von Sauerstoff und Luftfeuchtigkeit. In "Methoden der organischen Chemie". Ed. by Müller. I : 2, 321. G. Thieme, Stuttgart. 
Nickerson, W. J. 1943. Mycologia 35, 66.

Pasteur, I. 1876. Études sur la Bière. Gauthier-Villars, Paris.

Peynaud, E. and Domerco, S. 1956. Arch. Mikrobiol. 24, 266.

Prennig, N. and Wikín, T. 1960a. Pathologia et Microbiologia 23, 359.

Pfennig, N. and Wikén, T. 1960b. Zentralbl. Bakt. Il Abt. 113, 491.

Porter, J. R. 1946. Bacterial Chemistry and Physiology. J. Wiley \& Sons, Inc., New York.

Proceedings of the International Symposium on Enzyme Chemistry, Tokyo and Kyoto 1957. 1958. Pergamon Press, London.

REICH, M. and KAPENEKAS, H. 1957. Ind. Eng. Chem. 49, 869.

Santa María, J. 1958. Nature 182, 937.

Scherfers, W. A. 1961 . Experientia 17, 40.

Stephlinson, M. 1939. Bacterial Metabolism. Longmans, Green \& Co., London, New York \& Toronto.

Umbreit, W. W., Burris, R. H. and Stauffer, J. F. 1957. Manometric Techniques. Burgess Publishing Co., Minneapolis, Minn.

Verona, $O$, and Florenzano, $G, 1947$. Atti accad. naz. Ijincei, classe sci. fis., mat. e nat. 3,383 .

Voget, A. I. 1951 and 1957. A Textbook of Practical Organic Chemistry. 2nd Ed. and 3rd Ed., respectively. Longmáns, Green \& Co., London, New York \& Toronto.

VAN DER WALT, J. P. and VAN KiEkKEN, A. E. 1959a. Antonie van Leenwenhoek 25,145 .

Van der WaLt, J. P. and Van KERken, A. E. 1959b. Antonie van Leeuwenhoek 25,449 .

Walters, L. S. 1943. J. Inst. Brewing 49 (40, New Series), 253.

Walters, L. S. and Thiselton, M. R. 1953. J. Inst. Brewing 59 (50, New Series), 401

Weinland, E. 1906. Zeitschr. Biol. 48 (30, New Series), 87.

WERKMAN, C. H. and WoOD, H. G. 1942. Bot. Rev. 8, 1.

WIKÉN, T. and RICHARD, O. 1951. Antonie van Leeuwenhoek 17, 209.

WIKÉN, T. and RIChaRd, O. 1953a. Antonie van Leeuwenhoek 19, 279.

WIKÉN, T. and RICHARD, O. 1953b. Experientia 9, 417.

WIKEN, T. and RICHARD, O. 1954a. Antonie van Leeuwenhoek 20, 385.

WIKÉN, T. and RiCHARD, O, 1954b. Schweiz. Zeitschr. allgem. Path. Bakt. 17,475 .

Wikjén, T. and Richard, O. 1955a. Antonie van Leeuwenhoek 21, 337.

WıKÉN, T. and RıChaRD, O. 195̃ob. Schweiz. Zeitschr, allgem. Path, Bakt. 18,970 .

Wrkén, 1. and Pfinnig, N. 1957. Antonie van Leeuwenhoek 23, 113.

WikÉn, T. and PFENnig, N. 1958. Abstr. VIIth Internat. Congr. Microbiol. (Stockholm), 396.

WikÉ, T. and Prisnnig, N. 1959. Antonie van Leeuwenhoek 25, 193.

WIKĹN, T. 1961 . Sci. Rep. Ist. Super. Sanità 1, 309.

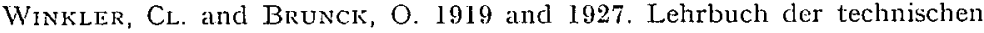
Gasanalyse. 4th Ed. and 5th Ed., respectively. A. Felix, Leipzig.

Z Elinsky, N. and Borisoff, P. 1924. Ber. Deutsch. Chem. Ges. 57, 150. 